\title{
AS CIÊNCIAS SOCIAIS EM SAÚDE: REFLEXÕES SOBRE AS ORIGENS E A CONSTRUÇÃO DE UM CAMPO DE CONHECIMENTO
}

Everardo Duarte Nunes*

\begin{abstract}
O trabalho aborda as origens, desenvolvimento e perspectivas das Ciencias Sociais em Saúde. Procura situar alguns pontos fundamentais relacionados a incorporaça de um pensamento social em saúde no Brasil e faz parte de um amplo movimento que ocorreu no p6s $20^{\circ}$ Guerra, principalmente junto aos Departamentos de Medicina Preventiva e Social. Trata da construçato desse campo do conhecimento, aponiando alguns trabalhos da literatura. Conclui apresencando algumas perspectivas em relaça d investigaça nesea área.
\end{abstract}

\section{INTRODUÇÃO}

Quando, há alguns anos atrás, em 1984, Renée Fox, uma das pioneiras da sociologia médica nos Estados Unidos, foi distingüida com um prêmio pela American Sociological Association, pelos seus trabalhos nesse campo do conhecimento, ela iniciou o seu discurso citando, do autor francés Charles Péguy, o seguinte: " ...com $\mathbf{4 0}$ anos o homem sente que a sua juventude começa a lhe escapar ... Na plenitude de sua melancolia, ele olha para trás, e torna-se um cronista e memorialista. $O$ que aconteceria se esta terrível melancolia continuasse a crescer na década seguinte? Felizmente, tal não é o caso. O quarentão não se torna um cinqüentão. Ele se torna um historiador" . Mais ou menos por esse caminho e pretensão é que eu gostaria de fazer esta apresentação. Dessa forma, eu não corro o risco de transformá-la num simples e desinteressante relato autobiográfico, ou como disse a socióloga que citei há pouco, "sucumbir a uma proustiana volta ao passado" (1).

Procurarei alguma correspondência com a lição de Wright Mills, quando dizia que no oficio do sociólogo, entre os valores do seu artesanato intelectual, ele devia " desenvolver e rever continuamente as opiniőes sobre os problemas de história, de biografia e de estrutura social, nos quais a biografia e a história se cruzam" (2).

\footnotetext{
- Docente do Departamento de Medicina Preventiva e Social da Faculdade de Ciencias Medicas, UNICAMP
} 
A tarefa a que me proponho será a de revisitar o campo das ciências sociais em saúde situando alguns aspectos referentes às suas origens e desenvolvimento e como vejo as suas perspectivas futuras. Mas, mesmo sem querer cair num relato personalizado, esclareço que a minha opção por esse campo de trabalho foi feita há vinte e cinco anos, quando se ensaiavam os primeros passos no ensino das ciências sociais em medicina e o campo não havia se institucionalizado (estaria hoje institucionalizado?), e a formação especializada inexistia no Brasil.

As origens de um pensamento social em saúde

De um modo geral, o movimento de incorporação das ciências sociais em saúde ocorre dentro dos processos gerais que se dão a partir do término da 2: Guerra Mundial. Muitas são as mudanças que acontecem em todos os países, afetando não somente a sociedade como um todo, mas provocando alterações em diversos níveis, como o educacional e o da saúde. Considerando a forte influência exercida pelos Estados Unidos, é interessante rever de maneira geral como ocorreu a progressiva introdução das ciências sociais em saúde naquele país. Lembre-se, ainda, que embora ocorram casos esporádicos de ensino das ciências sociais em escolas brasileiras (curso de Problemas de Sociologia Aplicada à Higiene, na Faculdade de Saúde Pública/USP, em 1946; curso de "Fundamentos sócio-econômicos", na Escola Nacional de Saúde Pública, do Rio de Janeiro, no início dos anos 50), o projeto inicial de introdução das ciências sociais irá acontecer cerca de duas décadas após os debates nos Estados Unidos.

Mesmo nos Estados Unidos, onde o fenômeno inclui-se nas ocorrências do pós-guerra, há precursores na sociologia médica nas primeiras décadas deste século. Mas, naquele momento, aparecia de maneira pouco distinta, associada à saúde pública e à assistência social. Interessante que a denominação de sociologia médica aparece em fins do século XIX em um trabalho de Charles McIntire, e no começo deste século em James P.Warbasse e Elizabeth Blackwell, obviamente com características muito diferentes das que assumiria mais tarde. No período de 30 a 50, em diferentes pontos dos Estados Unidos, a pesquisa sobre os fatores sócio-culturais na saúde estará presente: em Chicago, com Faris e Dunham(3), em Nova York, com os estudos de educação médica(4), em Yale, com pesquisas epidemiológicas (5). Há, também, duas 
outras vertentes de pesquisas, a histórica-social, com Sigerist(6) e os primeiros estudos sobre os fatores sociais na medicina, realizados por Stern( $)$, na perspectiva do materialismo histórico. Somente em 1951 é que Parsons(8) publicaria o trabalho que se tornaria consulta obrigatória na sociologia médica. Portanto, quando se instala, em 1954, o primeiro curso a nível de doutorado, em Yale, já existia um corpo inicial de pesquisas balizando o que se denominou de "ciências da conduta" ou " ciências do comportamento" . Em 1960 a sociologia médica será aceita como uma seção da American Sociological Association.

Para muitos estudiosos, o impulso dado ao campo esteve bastante relacionado ao estudo dos fatores sócio-culturais na etiologia das doenças mentais pelo fato de ter-se constatado alta prevalência de desordens psiquiátricas durante a seleção da popuilação masculina para o serviço militar, como também pelo aparecimento de sintomas psiquiátricos nos processos de reabilitação do pós-guerra.

Como se sabe, as condiçōes geradas no pós-guerra foram fundamentais para as transformaçōes ocorridas na América Latina, e que iriam se refletir principalmente naqueles problemas associados à industrialização, à migração do campo para a cidade e à expansão do sistema educativo.

Ao recuperar algumas informações que mostram como eram os convênios bilaterais entre o governo dos Estados Unidos e diversos paises laținoamericanos, observa-se que a prática médica é concebida pela poténcia hegemónica como fator de aumento de produtividade das classes trabalhadoras dos paises dependentes, assim como para buscar um consenso entre as naçóes. Na análise detalhada feita por García(9), verifica-se que, desde 1942 , havia um intenso interesse pelas questōes de saúde, sendo que os objetivos da Divisão de Saúde e Saneamento, do Instituto de Assuntos Inter-Americanos, eram os seguintes: a) do ponto de vista militar, melhorar as condições de saúde, sobretudo em relação às exigências de nossas forças armadas e às de nossos aliados norte-americanos; b) do ponto de vista político, cumprir as obrigaçōes deste governo em relaçăo aos programas de saúde e saneamento assumidas de conformidade com a Resoluçăo 30 da Conferéncia do Rio de Janeiro, de 15-28 de janeiro de 1942; c) do ponto de vista da produção, obter um aumento da produção de materiais essenciais em zonas onde existissem más condiçóes de saúde; d) do ponto de vista moral, demonstrar, 
através de fatos e não somente de palavras, os benefícios tangíveis da democracia em marcha e ganhar o apoio da população civil.

Andrade(10) lembra que, em relação à saúde, se consolidam, no período do pós-guerra, os sistemas de seguridade social, se nacionalizam e expandem as redes hospitalares, se promulgam leis que regulamentam o exercício da medicina, e os médicos começam a se organizar em associaçōes de caráter corporativista. Frente às novas situações criadas pelas políticas do pós-guerra, impunham-se, entre outras medidas, mudanças nos programas de formação de recursos humanos, notadamente os relacionados com a formação médica.

Tomando-se a orientação que foi imprimida aos currículos de ensino médico como uma das vertentes que possibilitaram a inclusão das ciencias sociais, verifica-se que isto foi produto de um longo processo desencadeado nos anos 50 através de inúmeros seminários e conferências ocorridos nos Estados Unidos, Europa e América Latina. No fundo da questāo estava a pretensão de reorientar a prática médica, formando profissionais portadores de um novo perfil, que seria adquirido em seus cursos de graduação, que deveriam possuir conteúdos curriculares inovadores. Nesses currículos destacavam-se as dimensões integral, preventiva e social. Com isso desejava-se romper a hegemonia do biológico na compreensão dó processo saúde-doença, do cuidado individual e intra-hospitalar como formas únicas e absolutas de prática médica. Na década de 60 , com a criação de uma grande quantidade de escolas médicas, a inovaçăo é năo somente a departamentalizaçăo em seu sentido mais amplo, mas a introdução dos departamentos de medicina preventiva e social. De um modo geral, surgem no interior desses departamentos quatro grandes áreas: Estatística, Epidemiologia e Saneamento, Organização e Administraçăo Sanitaria e Ciencias Sociais. Nesse cenário é que aparecem os primeiros cientistas sociais; auto-didatas em questóes de saúde, ensaiam os passos iniciais de uma atividade compartilhada com médicos, enfermeiras e assistentes sociais. Este contato enseja formas de atividades multiprofissionais através de trabalhos práticos, especialmente aqueles voltados para a comunidade, ponto crucial na proposta preventivista dos anos 60. Para isso necessitava-se de um instrumental metodológico que fazia parte da formaçăo dos cientistas sociais. Como relatei em outro artigo(11), caracterizo este período como " integração na prática", pois o papel do cientista social " não era somente o de estabelecer a metodologia para o diagnóstico da comunidade, 
mas, dentro do processo de ensino, acompanhar, juntamente com o médico e, em alguns casos, o assistente social, o estudante de medicina em visitas domiciliares. O material coletado nessas visitas e que incorporava tanto um conhecimento dos aspectos médicos, como sociais, culturais e psicológicos dos componentes da família, pretendia ser uma aproximação interdisciplinar e conduzia a um diagnóstico bio-psico-social" . Além disso, pretendia estender o conhecimento à comunidade como um todo e às suas instituições. Além de ser um projeto pedagógico, visava também que a comunidade iniciasse um processo de participação no encaminhamento dos seus problemas e tentativa de solução.

Em realidade, este projeto com essas características configura um segundo momento na introdução dos conteúdos das ciências sociais e que pode ser caracterizado como "teóricosaplicado" . Numa fase imediatamente anterior incluiram-se tópicos ou nocões conceituais de Sociologia, Antropologia e Psicologia Social sem vinculá-los à saúde, em cursos tidos pelos estudantes como " teóricos" e que despertavam muito pouco o seu interesse. Considere-se que o preparo anterior desses estudantes não lhes dava nenhuma formação em ciências humanas(12).

Não se pode esquecer que a questão do "desenvolvimento e organização da comunidade" faz parte de uma estratégia sócio-política mais ampla, ou seja, de tentar mobilizar aquelas parcelas da população que estavam à margem do desenvolvimento e que se situavam nas áreas urbanas mais carentes de recursos e infra-estrutura e que poderiam se tornar alvo fácil de tensöes sociais.

Toda a questão do modelo de "medicina comunitária", não somente como prática pedagógica, seria bastante criticada, principalmente quando a mesma foi situada no campo mais abrangente da prática médica - como forma de extensão de serviços e prática simplificada foi considerada como uma maneira de controlar, manipular e ordenar a comunidade(13). Também o caráter político de sua emergência e formas de intervenção serão objeto de contundentes análises críticas(14).

Todas essas questōes que envolviam, ainda, uma revisão das bases teరricas sobre as quais se assentavam o ensino e a pesquisa serão foco de atenção, em especial na década de 70. 
Isto não significa que antes desse período nada tivesse sido produzido. Interessante verificar que a questão dos " fatores sócio-culturais na saúde" já era pesquisada por antropólogos que trabalhavam junto a serviços de saúde, no final dos anos 30 e durante a década de 40. É o caso de Charles Wagley, que se encontrava no Brasil, desde 1939, a convite do Museu Nacional, realizando estudos na Região Amazônica para a instalação do Serviço Especial de Saúde Pública, onde permaneceu até 1946, tendo iniciado as atividades e assumido a direção da Divisão de Educação Sanitária. Juntamente com um consultor americano, define as primeiras diretrizes para um programa de educação sanitária dirigido aos escolares, aos setores populares das áreas rurais e das periferias urbanas(15). Na década de 50, outro antropólogo, Kalervo Oberg, realiza, a pedido do SESP e do Instituto de Assuntos Interamericanos, estudos de comunidades (no Pará, Espírito Santo e Paraná) a fim de subsidiar o planejamento sanitário (16). Não somente no Brasil, mas em outros países da América Latina, os primeiros cientistas sociais que se incorporam à area da saúde são os antropólogos. No caso da América Central e Panamá, estarão ligados principalmente às questōes nutricionais, junto ao INCAP (Instituto de Nutrición de Centroamérica y Panamá), e em alguns outros países, como Chile, Colômbia e Peru, às relações saúde/cultura de populações campesinas ou de estudos de profissionais que atuavam no campo da educação sanitária. Lembre-se que entre os organismos internacionais que tiveram a responsabilidade e patrocinaram os primeiros programas na área de Antropologia Médica no começo da década de $\mathbf{4 0}$ estavam, além do Instituto de Assuntos Interamericanos, já citado, a Oficina Sanitária Pan Americana, a Divisão de Saúde Internacional da Fundação Rockefeller e o Serviço Cooperativo Interamericano de Saúde Pública.

Assim, até a década de 60 assiste-se a um grande esforço em promover as ciências sociais na saúde, e que sem dúvida tem as marcas muito claras da influéncia norte-americana. Isto manifesta-se tanto a nível da proposta pedagógica, como no campo da pesquisa. Em relação à pesquisa antropológica, Sepulveda(16) realizou um levantamento das publicações na década de 50, arrolando menos de cinqüenta citações. Segundo o autor, estas investigações correspondem, em sua maioria, a estudos de casos " que são particularmente ilustrativos das complexas situaçōes que se produzem quando os integrantes das equipes de saúde entram em contato com as populaçőes ou comunidades latino-americanas". Para Menendez(17), a antropologia médica dominante 
entre 1930-60 pode ser " quase totalmente identificada com a etnomedicina, sobretudo nas décadas de 50 e 60" . Acrescenta que " esta produção não foi somente pouco utilizada pelo setor saúde, mas teve pouca vinculação com ele. Houve uma concentração no campesinato indígena, ignorando todos os outros setores sociais, incluidos os indígenas que migravam e se localizavam no meio urbano" . Ressalta que a teoria dominante foi o funcionalismo cultural.

A construção de um campo de conhecimento

Revisitar as origens e a formação de uma área do conhecimento que foi cortada por experiências que se completam - como o ensino e a pesquisa mas que apresentam desenvolvimentos diferentes, não se torna fácil, mesmo porque elas estavam ocorrendo num mesmo ambiente e sendo executadas muitas vezes pelos mesmos personagens. Dessa forma, o docente, ao mesmo tempo em que procurava dar conta de um campo teórico relevante às suas atividades de ensino, procurava desenvolver algum projeto de pesquisa que trouxesse contribuição mais duradoura à incipiente área. Não é estranho, por exemplo, que entre os trabalhos produzidos nos anos 60 figurem desde a proposta de ensino das ciências sociais baseadas no paradigma da história natural da doença, de García(18), à necessidade de conhecer de forma mais profunda os sujeitos sociais sobre os quais atuavam os cientistas sociais - os estudantes de medicina, objeto de um estudo prospectivo por mim realizado durante cinco anos. Tentava-se conhecer a motivaçăo à carreira e os valores que atribuiam a sua profissão no momento em que ingressavam na escola médica e durante os anos de graduaçăo(19). De outro lado, tanto escolas no Brasil, como em outros países, procuravam avaliar as suas atividades docentes buscando a melhor adaptação aos estudantes de medicina, visto que a grande maioria ingressava numa pratica de ensino num ambiente que lhe era estranho. Sem dúvida, o coroamento desta análise avaliatória, iniciada em 1965 e publicada em 1972, será o livro de García sobre a educaçăo médica na América Latina, que irá revelar, numa perspectiva teórica calcada no materialismo histórico, qual era a situação do ensino da medicina preventiva e social e em particular das ciencias da conduta(20).

Foi a partir dos anos 70 que começaram a ocorrer importantes eventos na área das ciencias sociais em saúde. De um certo modo, percebia-se clara 
insatisfação com os modelos de ensino e com a bibliografia que vinha sendo utilizada. Principia-se a estabelecer intensas críticas ao modelo da história natural da doença e à literatura basicamente funcionalista que as escolas adotavam(12). Entre as primeiras denúncias, Gaete y Tapia (21) expressam que " Em nossa opinião, o que deve ser feito neste momento é discutir a orientação teórica que deve ter o trabalho dos cientistas sociais neste campo. Tal discussão ainda não foi realizada, e estão sendo utilizados marcos teóricos e técnicas de investigação cujas possibilidades parecem limitadas e limitantes. Dessa forma, as ciências sociais em medicina têm neste momento duas alternativas: ou permitem reformular o conceito de medicina e ampliar a compreensão dos problemas de saúde oferecendo uma perspectiva de grande significado em uma sociedade subdesenvolvida como a nossa, ou se limitam a entregar somente alguns elementos de juizo que possibilitem à equipe de saúde um desempenho mais integral, porém indubitavelmente constrangido ao âmbito estritamente pessoal como tem ocorrido até agora" . Em realidade, esse constrangimento teórico foi sentido por ocasião de alguns seminários realizados sob os auspícios da OPAS (Organização Pan Americana da Saúde), em Ribeirão Preto, Campinas e Buenos Aires, sobre metodologia e ensino das ciências sociais em saúde. Criticar o funcionalismo e repensar as ciências sociais em saúde dentro de uma discusão epistemológica passa a ser uma das principais propostas, a desenvolver-se nos anos 70 e seguintes. No ideário criado por cientistas sociais e médicos em 1972 no Seminário que se reuniu em Cuenca (Equador), o modelo alternativo propunha: centrar-se na análise da mudança, incluir elementos teóricos que permitissem pesquisar a realidade em termos de suas contradiçōes internas, permitir a análise tanto de níveis específicos da realidade como de níveis estruturais e as relaçōes entre ambos(22). Se, na fase anterior, havia a presença marcante de autores como Parsons(8), Goffman(23), Bloom(24), Mechanic(23), a partir de 70 aparecem como consultas obrigatórias Polack(26), Berlinguer (27) Rosen(28), Freidson(29) e para os estudos epistemológicos, Canguilhem(30), Bachelard(31), Foucault(32), Bourdieu(33), Fichant e Pecheux(34). Reler capítulos de "O Capital" e tomar o clássico de Engels "A situaçăo da classe operária na Inglaterra" como precursor da Epidemiologia Crítica faz parte desse movimento que incorpora em suas análises o materialismo histórico e dialético, também retomado muitas vezes através dos seus críticos, como Kosik(35), Lukács(36), Althusser (37), Poulantzas(38), Gramsci(39). A utilização da Escola Crítica de Frankfurt (Adorno, Horkheimer, Habermas) irá ocorrer a partir da segunda metade dos anos 80 , não impedindo que alguns dos autores consagrados em 
décadas anteriores continuassem a fazer parte do arsenal teórico dos pesquisadores.

Tendo, portanto, suas origens fortemente vinculadas às concepções estrutural-funcionalistas, a sociologia médica aparece entre nós incluida em um campo mais amplo e muitas vezes sob a denominação de " ciências sociais aplicadas à medicina" ; iria, a partir dos anos 70, empreender um profundo questionamento desses modelos explicativos. No citado Seminário realizado pela OPAS, em 1972, o modelo alternativo deveria considerar, em sua construção, o seguinte:

1 "As relaçōes entre o conceito de saúde, os modos de produção e as formações sócio-econômicas.

2 As relações entre a organização das ações de saúde, os modos de produção, as formaçōes sócio-económicas e os conceitos de saúde.

3 As investigaçōes históricas sobre a formação e o desenvolvimento e a consolidação das organizações práticas e da educação médica no Continente. Estas investigaçōes deverăo inscrever-se dentro da relação dinâmica entre modos de produção e formaçóes sócio-económicas específicas, e a definição epistemológica das relações entre as ciências sociais e as ciências biológicas concordantes com este novo modelo.

4 As atividades de análise, investigação, compilação bibliográfica e produção de monografias que permitam enriquecer o marco teórico proposto" (22).

Em novembro de 1972, no mesmo ano, portanto, da realização do Seminário de Cuenca, García(40) escreveu para o XXIII Congresso Internacional de Sociologia, realizado em Caracas, Venezuela, um trabalho que, sob o título de "As Ciencias Sociais em Medicina" , traçava um esquema que poderia servir como orientador nas pesquisas que levassem em consideração a discussão de aspectos até então năo contemplados na análise funcionalista. $O$ esquema incorporava: a) localizaçăo da medidcina na estrutura social; b) influencia da estrutura social na produção e distribuiçăo da doença; c) análise da estrutura interna da produção de serviços médicos; d) a relação da formação de pessoal de saúde com o campo médico.

Muitas análises foram realizadas, evidenciando a importancia que teve para a área da saúde a perspectiva do materialismo histórico, por exemplo em 
Mercer(41), Teixeira(42),Donnangelo(43), Nunes (44). Para Teixeira, " a incorporação das ciências sociais à medicina, constituindo a problemática da saúde coletiva, não se deu de forma aleatória, mas sim tratou-se de um recorte sistemático, uma incisāo profunda no interior mesmo daquelas ciências a partir da inscrição dos conteúdos disciplinares no método histórico-estrutural" .

Ao lado de uma " nova" perspectiva teórica que irá conduzir a produção científica na área a partir dos anos 70 , uma outra perspectiva abre-se nesse período, com a instalação dos primeiros cursos de pós-graduação em medicina social, no Brasil (Rio de Janeiro) e México (Xochimilco). Deve-se lembrar que até a segunda metade dos anos $\mathbf{7 0}$ os cursos para a formação especializada em ciências sociais no campo da saúde somente eram possíveis nos Estados Unidos e em alguns países europeus, sendo que os cientistas sociais brasileiros realizavam seus mestrados e doutorados nas faculdades de filosofia, escolhendo a temática da saúde para as suas dissertações e teses, embora muitas vezes já fossem docentes em faculdades de medicina ou de saúde pública. Em realidade, os cursos que se instalam nos anos 70 , junto aos departamentos de medicina preventiva e social, ou em institutos de medicina social, não se destinavam à formação de cientistas sociais, sendo que muitos deles, embora dessem grande espaço às ciências sociais, não estavam abertos aos graduados nessas cièncias, destinando-se a médicos. Somente em data recente passaram a admitir outros profissionais, incluindo cientistas sociais, como é o caso do curso de pós-graduação em Saúde Coletiva, da UNICAMP e o de Medicina Social da UERJ; o curso realizado na Bahia, denominado de Saúde Comunitária, também é multiprofissional.

Sem dúvida, pode-se dizer que foi a partir dessa época que se inicia uma fase de institucionalizaçăo da área, sendo que para Mercer(41) o período de 1975 a 1980 pode ser denominado de "identidade e legitimaçăo". Para ele é quando ocorre uma convergencia de vários pontos entre os pesquisadores latino-americanos: busca de um balizamento teórico, realização de pesquisas empíricas que "tendem a romper a rotina do discurso teorizante" e a formaçăo de recursos humanos. Continua, afirmando: "As pesquisas realizadas contribuem para expandir a conviç̧ão de que a abordagem sociológica era possível e necessária".

Avaliaçőes realizadas no Brasil iriam apontar que mesmo enfrentando problemas, tanto a nível do ensino, como da investigação, no primeiro caso 
por motivos inerentes à própria estrutura dos cursos em saúde que enfatizavam aspectos técnicos e biológicos e, no segundo, pela oscilante política de apoio aos programas para a produção na área de saúde coletiva, são evidentes os esforços no sentido de dar continuidade ao projeto das ciências sociais em saúde. No período de 1968-75, a FINEP apoiou 29 projetos de pesquisa, de 1975-79, 58 trabalhos de pesquisa e de 1986-87, 28 projetos, o que neste último período representava $20,6 \%$ dos projetos financiados junto ao Programa de Saúde Coletiva. Do total de 136 projetos desse programa, 51,5\% eram financiados pelo CNPq, 19,8\% pelo MS/SCT e 8,1\% pela OPAS(45).

Em relação ao ensino reporto-me a duas investigações que situam a questão. Na primeira, os dados se referem à década de 80 e mostram que entre 44 escolas de medicina 26 ministravam disciplinas ou temas de ciências sociais, sendo que em cerca de $66,0 \%$ dessas escolas havia uma disciplina isolada de Ciências Sociais. Em quase a sua totalidade a disciplina havia sido criada a partir de 1965, sendo que do total de 37 docentes envolvidos no ensino, 16 tinham formação básica em Ciências Sociais ou Sociologia(46). A segunda investigação, realizada em 1987 , está relacionada ao ensino a nível da pós-graduação, abrangendo 8 cursos de Mestrado e Doutorado em Saúde Coletiva, nos quais as Ciências Sociais aparecem como disciplinas obrigatórias(47).

Em trabalho recente, utilizando informaçōes colhidas em 1990, Spinelli (89), através de 58 questionários respondidos por profissionais que atuam na área da saúde, detectou que 32 deles eram graduados em Ciências Sociais, 18 na área de saúde e 8 na área de Humanas (inclui-se aqui o Serviço Social). Muitos dos cientistas sociais haviam realizado cursos de especialização em Saúde Publica; aponta, também, que $50 \%$ dos cientistas sociais haviam concluído o curso de graduaçăo entre 1965 e 1974. São dados preliminares e serăo completados à medida que forem recebidos mais questionários já encaminhados.

Numa análise que pretende percorrer, mesmo de maneira geral, este campo do conhecimento, um ponto que não pode ficar sem referência é o da produção científica. Mesmo porque é através dela que se pode constatar os caminhos que a área vem percorrendo ao longo do tempo. Em realidade, em outros pontos desta apresentação já foi feita alusăo ao fato da importancia que tiveram nos anos 70 as mudanças nos enfoques teóricos na abordagem 
dos problemas de saúde. Mas, como lembra Donnangelo(43), as tendéncias que vão se manifestar a nível dos estudos e pesquisas, colocando ênfase na questão das práticas de saúde e na relativa superação do projeto original da medicina preventiva, cuja aderência à clínica ainda era manifesta, " podem ser remetidas, por particularização, à intensidade e ao significado das reordenaçōes da prática médica no Brasil. Mas derivam fundamentalmente sua explicação das diferenças entre a estrutura social na qual foi gerada a proposta preventivista e a estrutura social brasileira, com suas específicas formas de manifestação de contradições e conflitos" . A autora chama a atenção para a diversidade que irá ocorrer na produção na área, tanto relacionada à temática, como pela ênfase em distintos objetos e campos do saber, assim como pela própria metodologia empregada. Para ela, as variações que ocorrem derivam das distintas conotaçōes assumidas pela noção de coletivo. Estas têm sido amplamente reproduzidas em trabalhos posteriores, e sem dúvida constituem uma classificação bastante oportuna e ponto de partida para muitas reflexões, quando assinalam que o coletivo pode ser entendido como: coletivo/meio; coletivo/conjunto de indivíduos; coletivo/interaçăo entre elementos; coletivo/como conjunto de efeitos ou conseqüencias da vida social; coletivo/transformado em social como campo específico e estruturado de práticas.

Ao sistematizar a produçăo científica que se inicia na segunda metade dos anos 70 até 1980, Donnangelo adota separá-la em duas grandes áreas: 1) produçāo epidemiológica restritivamente entendida como estudos sobre saúde-doença em populaçóes; 2) produção de estudos sobre práticas de saúde. Posteriormente, ao levantar a produçăo latino-americana em ciencias sociais aplicadas à saúde, para o período de 1980-85, Nunes(48)acompanharia a classificação utilizada em trabalho anteriormente realizado pela OPAS(49), onde figuram quatro categorias de estudos: medicina tradicional, processo saúde-doença, serviços de saúde e formação de recursos humanos.

Torna-se extremamente díficil referir-se de forma detalhada a essa produção; assim sendo, a opçáo é comenta-la em largos traços. Uma primeira observação é que, tanto no levantamento bibliografico sobre a produçăo de 1950 a 1979 como no de 1980 a 1985, o critério de inclusăo dos trabalhos é bastante amplo, ou seja, estāo presentes não somente aqueles com quadros teóricos claramente definidos, como também aqueles que utilizam variáveis sociais, económicas, políticas e culturais. Isto, obviamente, concorre para que 
se detecte uma grande quantidade de trabalhos. Assim, para o período de 1950 a 1979 são levantadas 1663 referências e para 1980 a 1985, 1086 referên. cias bibliográficas. Distribuidas pelas quatro categorias acima referidas temos as seguintes proporções: $18.4 \%$ em medicina tradicional; $36,35 \%$ em serviços de saúde; $32,2 \%$ em processo saúde-doença e 13,0\% em formação de recursos humanos.

Alguns comentários já foram feitos sobre a presença da Antropologia e, em realidade, a produção contida em medicina tradicional é majoritariamente antropológica e se faz presente especialmente nos anos 50 e 60 . O recrudescimento desta produção irá ocorrer no final da década de 70 e início dos anos 80. Nesse momento as pesquisas irão incorporar como campo de estudo os problemas da sociedade urbano-industrial e retomar os estudos sobre as chamadas " práticas populares de saúde" . Neste caso, procurava-se dar algum tipo de resposta às urgentes solicitações manifestadas nas propostas de atenção primária de saúde nas quais a extensão de cobertura e a participação comunitária são básicas. Não se pode deixar de citar o oportuno comentário de Menendez(17), ao referir-se a essa questão, quando associa o projeto da atenção primária como uma forma de enfrentar a crise financeira e de eficácia dos sistemas médicos oficiais sobretudo em relação com as populações subalternas, especiamente aquelas que residem na zona rural e na periferia dos centros urbanos. Segundo Menendez,durante os anos 70 e 80 "descobre-se" que são esses grupos que continuam sendo os que apresentam as maiores taxas de mortalidade e que têm as menores coberturas de serviços e atividades médicas , com os maiores problemas de desnutrição, alcoolismo e doenças infecto-contagiosas.

Como apontado em trabalho anterior, Nunes(41), na década de 50 e 60 os trabalhos apresentavam-se dentro de uma linha culturalista (Menendez denomina de funcionalismo culturalista) onde predominava a análise de valores, atitudes e padróes culturais, e nos anos 70 e 80 encaminha-se para uma abordagem teórica de caráter histórico-estrutural. Nessa perspectiva são realizadas, entre outras, algumas investigaçőes sobre práticas alimentares que concluem que essas práticas não podem ser simplesmente explicadas por motivos culturais(50).

Em termos de um trabalho que sintetiza aspectos da medicina tradicional na América Latina, pode-se consultar Goldwater(51), que analisa a teoria e 
terapia humoral, as categorias quente e frio como reações básicas e suas relações com a saúde, os métodos de diagnóstico e a utilização de plantas e traça algumas idéias sobre o espiritismo no Brasil. Em relação ao Brasil, Queiroz e Canesqui(52) realizaram uma análise geral da produção científica, em especial a dedicada às representações de saúde e doença e práticas de cura.

Na categoria Serviços de Saúde a diversidade de temas e sub-temas é bastante grande, e os mais expressivos tratam das relaçōes medicina e șociedade, medicina estatal, análises históricas e programas de saúde. $O$ estudo da articulação da prática médica com a prática social terá um destaque especial, inclusive pela proposta téorica calcada no materialismo histórico, e que será a tônica dos estudos na segunda metade dos anos 70. Lembre-se que o trabalho de Donnangelo "Medicina e Sociedade" foi publicado em 1975(53). Na mesma época, Arouca(54) elabora um estudo crítico sobre a medicina preventiva, que, recorrendo à metodologia foucaultiana de análise do discurso e à proposta teórica althusseriana, não somente reconstitui a "arqueologia " desse campo do conhecimento, como elabora algumas questóes que se tornariam fundamentais em posteriores discussóes e trabalhos, como é o caso de entender o cuidado médico como um processo de trabalho que tem como objetivo a intervenção sobre os valores vitais e ao atender necessidades humanas é uma unidade de troca à qual é atribuida, social e historicamente um valor. Poucos anos depois, autores como Nogueira(ss) e Gonçalves(so) iriam realizar importantes estudos sobre a prática médica, no primeiro caso articulando-a ds características políticas, ecónomicas e ideológicas de cada sociedade - a sociedade grega, medieval e moderna capitalista; no segundo caso, como prática social articulada des demais práticas, no modo de produção capitalista. Como analisa Pereira(st), no trabalho de Gonçalves " a prática médica năo foi vista apenas respondendo a solicitaçóes da estrutura social na qual se insere, mas também contribuindo, como sujeito, para a constituiçăo, manutençăo, reproduçăo e transformaçăo dessa estrutura" . Ambos os trabalhos datam do final dos anos 70, o primeiro de 1977 e o segundo de 1979, e aparecem numa sequencia de trabalhos que teve na tese de Donnangelo(14), "Saúde e Sociedade", de 1976, uma vertente teórica extremamente fértil e inspiradora. A própria Donnangelo (43), em trabalho onde analisa a pesquisa brasileira na década de 70, considera que embora nesse período os temas do planejamento e da reorganizaçăo ou da rearticulaçăo dos serviços mantenham-se constantes "inicia-se uma linha de pesquisas que våo progressiva- 
mente buscando evidenciar com maior ou menor refinamento metodológico as articulações econômicas e político-ideológicas da prática sanitária na sociedade brasileira". Serão marcantes ainda nesse período os trabalhos de Braga(58), Luz (39), e no início dos anos 80 ocorre a publicação do primeiro trabalho que analisa a previdência social, de 1945 a 1960, como um "processo pelo qual as questões previdenciárias convertem-se em questões políticas" , de autoria de Cohn (60). O estudo sobre os convênios com a previdência, de Giffoni(61), data de 1981 e somente na segunda metade dos anos 80 Oliveira e Teixeira(62) retomam a questão da previdência.

Constitui tarefa extremamente difícil analisar todos os estudos que podem ser catalogados dentro da ampla categoria que foi adotada - Saúde e Sociedade. Lembraria, do ponto de vista da reconstituição histórica, a importancia da pesquisa realizada por Machado e colaboradores(63)sobre as origens da medicina social e constituição da psiquiatria no Brasil, assim como os trabalhos de Luz(64) sobre as políticas e instituições d saúde no Brasil de 1850 a 1930 e os de Mehry(65)sobre a história da saúde pública no Estado de São Paulo. De outro lado, os pesquisadores sentiram a necessidade de aprofundar o conhecimento do próprio movimento sanitário, e entre os trabalhos podem ser citados Labra(66) e Escorel (67) e, sobre o movimento entre os profissionais médicos, o trabalho de Campos(68). Acrescente-se, ainda, que os anos 80 também trarão novas perspectivas nos estudos sobre o mercado de trabalho e profissōes de saúde, assim como sobre insumos para serviços de saúde. Neste último caso, o grande destaque será na análise do medicamento como mercadoria ou relacionando o consumo ds classes sociais(69), ou ainda sobre a indústria farmacêutica(70).

Se, especialmente para o Brasil, a grande fonte geradora de trabalhos de pesquisas situa-se no campo que vem sendo denominado de organização das práticas de saúde, e que se estende 20 longo da década de 80 , inclusive subsidiando a discussão sobre a reforma sanitária(71) e encaminhado-se para a compreensão dos movimentos sociais em saúde(72), em alguns paises latinoamericanos, México e Equador, a abordagem do processo saúde-doença tornou-se uma das mais férteis experiéncias no sentido de entender como o processo biológico, sendo um fenómeno natural, assume formas históricas definidas. Não se pode deirar de mencionar que a escola mexicana, com os trabalhos de Laurell(73), da escola equatoriana, com as pesquisas de Breilh(74), de Franco(75) na Colómbia, e, no Brasil, os trabalhos de Tambellini(7) serão fun- 
damentais no encaminhamento da chamada Epidemiologia Social ou Epidemiologia Crítica.

Embora grande parte da produção epidemiológica ainda se refira a fatores e não a processos, percebe-se que gradativamente, como lembrava Donnangelo (43), " o social já não aparece sob a forma de uma variável adicionada ao elenco de fatores causais da doença mas como um campo estruturado no interior do qual a doença adquire um específico significado social" . Como exemplos citam-se as pesquisas sobre a doença de Chagas, relacionando-a à estrutura agrária; ao processo migratório; ao trabalho urbano e ao espaço social $(77)$. Trabalhos como o de Barata (78) sobre a epidemia de meningite e 0 de Ruffino e Pereira(79) sobre a tuberculose no Rio de Janeiro ilustram como a doença pode ser melhor compreendida quando tomada em suas dimensões histórica e política.

Dentro da classificação que adotamos, a que se apresenta menos desenvolvida em relação à utilizaçăo de marcos sociológicos de análise é a de formação de recursos humanos. Já em 1983 Nogueira(80) apontava, ao revisar a literatura de 1966-1982, que existiam poucas investigaçōes baseadas em fontes primárias de dados; que a preocupação principal era com o currículo e a organização do ensino universitário; que começava a ganhar espaço a questão do pessoal auxiliar, e não se estudava a questão da ideologia e dos movimentos profissionais. Agumas análises críticas da medicina preventiva aparecem nos anos 80(81) e dois estudos sobre a educação médica são relevantes: o realizado por Schriber (82) e o de Lima(83); ainda sobre este tema, os egressos do curso médico seriam o objeto de pesquisa de Ribeiro(s).

Sabemos perfeitamente que as citaçőes não cobrem toda a literatura produzida, e as referidas neste trabalho contribuem para, de uma forma muito geral, dar os contornos do campo das ciéncias sociais em saúde. Há notáveis trabalhos realizados após 85 e que merecem uma análise especial, mas que infelizmente não se torna possível neste momento. $O$ crescente número de teses e dissertaçóes necessita ser revisado para, assim, fornecer um balanço mais detalhado. Não se pode deixar de mencionar a importancia que passa a ser conferida à própria questáo da metodologia a ser utilizada na área das pesquisas em saúde coletiva, exemplificada pelo trabalho de Minayo(8s). Isto reconduz a um campo de preocupaçóes que, nos anos 80 , teve em Pereira(s7), quando realizou uma circunstanciada análise de como os métodos 
funcionalista, da compreensão e o dialético haviam sido utilizados em investigaçōes sobre a organização social das práticas de saúde, um dos primeiros sistematizadores que procurou entender o que estava ocorrendo com a " explicação sociológica em medicina social" . Mais recentemente, Luz(86) irá se dedicar a analisar o desenvolvimento sócio-histórico da racionalidade científica moderna, " através do exame de algumas categorias estratégicas comuns a duas disciplinas do social: a medicina e a sociologia, privilegiando a medicina na análise" .

Perspectivas em Ensino e Investigação em Ciências Sociais e Saúde

A tentativa de apresentar um quadro geral da situação deste campo do conhecimento impöe, a esta altura, alguns esclarecimentos. $O$ primeiro refere-se à denominação " ciências sociais em saúde" , que se tornou usual entre os que desenvolvem atividades docentes na área de saúde pública e medicina social. Em realidade, disciplinas com a denominação de sociologia médica, ou da saúde, antropologia médica, economia da saúde, comuns entre norte-americanos e europeus, tem um desenvolvimento bastante recente entre nós. Seguramente, a questão da denominação torna-se, sob certos aspectos, secundária, na medida que o fundamental está no equacionamento da proposta que visa não somente compreender a dimensão-social das práticas de saúde, mas também como o processo saúde-doença é, em esséncia, um processo social. De outro lado, a maior enfase nos aspectos sociológicos, antropológicos, políticos ou econômicos está relacionada não somente à formação do pesquisador, como principalmente ao tema e aos objetivos da investigação. Uma simples leitura dos objetivos de alguns cursos de pós-graduação corroboram a afirmação acima. Por exemplo, são citados como objetivos do Mestrado em Saúde Coletiva/UERJ: "...desenvolver instrumentos de reflexăo sobre a medicina como prática social, analisando a génese e desenvolvimento do saber e das práticas de saúde, bem como das dimensóes técnicas, económicas e político-ideológicas" ; do Mestrado em Saúde Comunitária/UFBA:

"...compreende a investigação dos determinantes da produção social das doenças e da organizaçăo social dos serviços de saúde e o estudo da historicidade do saber e das práticas sobre 03 mesmos" (87).

De um modo geral, pode-se considerar que o desenvolvimento desta área constitui um projeto em andamento e tanto em relaçăo ao ensino como 
à pesquisa há necessidade de aperfeiçoamentos. Em relação ao ensino, e aqui refiro-me ao de graduação de estudantes da área da saúde, o problema não se constitui em discutir a validade de introduzir ou não as ciências sociais; esta discussão foi superada na medida em que a " saúde como questão social" passou a ser de aceitação universal. A questão básica é a de encontrar formas adequadas à transmissão dos conteúdos, considerando-se, inclusive, que no momento a literatura nacional já conta com expressivo material, situação muito diferente do que ocorria há quase três décadas, quando a bibliografia aplicada à área da saúde referia-se a uma realidade que não a nossa. De outro lado, o fato de as ciências sociais terem sido introduzidas no interior da escola médica junto a departamentos considerados "marginais" concorreu para cercear a sua expansão, acrescentando-se a isso que muitos docentes não tinham formação especializada em ciências sociais. Interessante que, entre nós, o fato de alguns cursos terem associado às ciéncias sociais a palavra " aplicadas à saúde" foi visto por muitos como uma área de menor expressão, no mínimo como ateórica, como também a idéia de que a escola médica, obviamente com a maioria do seu pessoal docente procedente da área biológica e pelo status dominante da profissão, é que determinava as linhas de pesquisa dos cientistas sociais. Se isto aconteceu em algumas escolas, até onde vai o meu conhecimento sobre a questão, a situação foi bastante diferente do que ocorreu nos Estados Unidos. Ugalde(88), citando trabalho realizado por Maikovich, aponta que nos Estados Unidos as ciencias sociais em saúde, surgindo à sombra dos hospitais universitários, estiveram sob o domínio da medicina marcando profundamente as investigaçōes, sendo que os temas escolhidos para investigaçăo sociológica "refletiam uma clara parcialidade dos interesses da poderosa profissão médica norte-americana" . Dessa forma, a ênfase em investigaçóes era sobre a percepçăo que os médicos tinham dos pacientes, e năo o contrário; sobre a organizaçăo dos hospitais e sobre modelos sócio-psicológicos na utilizaçăo dos serviços médicos. Somente anos depois, com a participaçăo de pesquisadores com formação marxista, como McKinlay, Navarro, Waitzkin, Watermann, é que o questionamento político, económico e ideológico da medicina e da saúde começa a ser abordado. No Brasil, assim como em outros paises latino-americanos, a situação foi diferente, pois " Enquanto a teoria social que se desenvolvia nos Estados Unidos era conservadora, a aplicaçăo das ciencias sociais na América Latina tinha uma orientação claramente progressista, e de acordo com as classes dominantes latino-americanas, subversiva" (88). São conhecidas as reaçōes das forças militares relacionadas à repressão ao ensino das ciências 
sociais, levando ao exílio muitos dos seus mais importantes professores e pesquisadores. Com isto não quero afirmar que as reações negativas dos estudantes de medicina às ciências sociais fossem devidas exclusivamente à questão ideológica e ao seu caráter crítico; a resisténcia também se devia ao fato de que, pelas suas próprias caracteristicas, elas se contrapunham ao modelo de conhecimento que a escola médica tradicional tem como base para a formação profissional e que é càlcada num ciclo básico com ênfase nas ciências biológicas e um ciclo profissional que objetiva a especialização. Obviamente, a conquista de um pequeno espaço tornava-se uma grande vitória: constituir-se como disciplina obrigatória era a primeira delas. Tentar integrar-se com outras disciplinas sempre foi uma tarefa praticamente impossível, visto que a interdisciplinaridade nunca foi desenvolvida pelos departamentos, embora constituisse ponto fundamental no seu ideário desde as suas origens nos anos 60 .

Continuar trabalhando a questão do ensino é de fundamental importancia, considerando-se que as possibilidades de introduzir as ciências sociais ampliou-se além da graduação, abrangendo cursos de pós-graduação, especialização e residéncias médicas. Cada um deles tem uma problemática de ensino diferente e demanda estratégias pedagógicas distintas . O trabalho de Spinelli(89), citado anteriormente, chama a atenção para o fato de que é no ensino que se observa " o grande aproveitamento dos profissionais, absorvendo a maior parte do tempo deles, seja a graduaçăo de profissionais de saúde (32 em Medicina, 16 em Enfermagem, 6 em Nutriçäo especificamente em cada curso, fora as múltiplas participaçőes; apenas 5 não mencionaram a graduação)" .

Em relaçào à pesquisa, os quatro campos citados continuam a desafiar os estudiosos. As análises antropológicas tem a sua frente o estudo das práticas populares de saúde e suas relaçöes com a estrutura social e seus aspectos ideológicos, integrando, como escreve Menendez(17), "as dimensóes cultural e económico-política" .

A área de serviços de saúde, e que em realidade é mais ampla do que o nome pode sugerir, pois refere-se d̀ organização social das práticas de saúde, mostrou-se ao longo dos últimos anos altamente produtiva. A temática é diversificada e muitos dos assuntos que foram enunciados e mesmo pesquisados deverão ser objeto de reflexăo nos próximos anos. Refiro-me em especial 
ao papel do Estado e à questão das relações de poder, tanto as que se manifestam a nível técnico, administrativo, como político e ideológico. Alguns estudiosos da área têm apontado a procedência das análises que contemplem a relação Estado-setores populares, o que conduziria a conferir especial destaque ao estudo dos movimentos sociais em saúde.

Em relação à área de estudos sobre o processo saúde-doença, o campo continua a exigir um esforço redobrado, considerando-se que a interrelação entre o biológico e social coloca, de um lado, problemas de natureza epistemológica que necessitam ser analisados, e, de outro, a necessidade de dar resposta aos problemas sanitários que se tornam cada vez mais agudos. Nesse sentido, tornam-se fundamentais estudos que estabeleçam as articulações entre a crise e a situação de saúde. Dessa forma, pesquisar a deterioração das condições de vida que vem ocorrendo entre elevados contingentes populacionais, constitui ponto de partida para traçar o seu perfil epidemiológico. É evidente que estas questões têm que ser analisadas considerando dimensões que especifiquem as transformaçōes nos processos de trabalho, nos padrōes de relações sociais e na distribuição do espaço social. Como apontei em outro trabalho, considero que: "Basicamente será através das categorias referidas aos processos de produção e reprodução social, expressados na diferenciação em classes sociais que se poderá compreender melhor as relaçōes da crise com os processos saúde-doença. Continua sendo importante investigar o impacto da urbanização e seu significado e implicações na saúde; o processo de migração acelerado pela crise e suas relaçöes com a doença, inclusive as mentais." Seguramente, a relaçăo trabalho-saúde continuará sendo um objeto de estudo da maior relevancia, que, como escreveu Laurell(90), trará amplas possibilidades para o entendimento da "interrelação dinâmica entre o social e o biológico, postulando, sem dúvida, a subordinação do segundo ao primeiro" , quando conclui que "o processo saúde-doença não está socialmente determinado, mas que tem caráter social em si mesmo" .

No último grupo de trabalhos revisados, o da formação de recursos humanos, há, entre outras questőes a investigar, a que se refere à continuidade de projetos que dimensionem as relaçóes entre o trabalho dos profissionais de saúde e as políticas de saúde. Certamente, no campo específico das questöes educacionais, quanto ao ensino das ciencias da saúde, a análise sociológica, muito pouco realizada entre nós, não pode deixar de ser citada como um campo aberto à investigação. 
É óbvio que a pesquisa não pode deixar de ser equacionada frente às situações da política científica do país e das formas institucionais que possam concorrer para a efetivação de recursos financeiros, sem os quais ela se converte em mera possibilidade, ou, na melhor das hipóteses, num trabalho individual, cujas finalidades ficam limitadas à obtenção de um título acadêmico e com uma divulgação muito limitada.

Quando em recente trabalho tentei traçar elementos que configurassem a Medicina Social na América Latina, deparei-me com uma questão que não podia ser deixada de lado, pois ela atingia praticamente todos os problemas que a sociedade vem enfrentando neste final de século e que se enuncia com a palavra crise. Naquele momento escrevi: "Sem dúvida, a crise e sua problematização não são exclusividade da medicina social. Ela penetra outros campos do conhecimento e a discussão de novos paradigmas reaparece nos anos 80. Ademais, não é possível entender a crise do conhecimento como um fato isolado. De fato, no mesmo período, especialmente em seu final, foram aprofundadas as análises críticas tanto das práticas político-sociais do capitalismo como do socialismo. Não sendo este o espaço para avançar uma caracterização da crise, convém assinalar que a leitura das crises políticas têm perspectivas distintas se são feitas a partir dos países da Europa Oriental, dos Estados Unidos, dos países da Europa Ocidental, ou dos países dependentes, incluindo logicamente os latino-americanos". Buscar inspiração na análise feita por Ianni(91) quando tratou da crise dos paradigmas em sociologia pareceu-me a mais adequada. Ao revisar a longa trajetória que se inicia após a $2^{z}$ Guerra Mundial e se intensifica na atualidade, o autor escreve: " Uns se colocam radicalmente em favor de novos paradigmas. Outros propóem renovações ou desenvolvimentos dos clássicos, incorporando aí contribuições contemporaneas. E há os que reconhecem que a criação de novos paradigmas não implica necessariamente na desqualificação dos outros. Mesmo porque, na história do pensamento sociológico, ao lado das oposições e rupturas, registram-se também convergências e continuidades." A síntese que Ianni oferece em seguida é extremamente esclarecedora e, ao citá-la, retomo-a não somente como encaminhadora das discussóes na Medicina Social, mas, em especial, para o campo das ciências sociais em saúde. "No conjunto discutem-se problemas relacionados tanto ao método como ao objeto da sociologia. Discutem-se prioridades ou acomodaçőes, quanto à indução quantitativa e qualitativa, à análise sincrónica e diacrónica, ao contraponto das partes 
e do todo, à dinâmica e à estabilidade sociais, ao indivíduo e à sociedade, ao objetivo e subjetivo" . Sem dúvida, os impasses das ciências sociais em saúde não se situam fora desses problemas, mesmo porque, ao situar-se como parte do conjunto das ciências sociais, reflete com maior ou menor intensidade, e com as diferenças que the são peculiares pelo objeto que aborda - a saúde - as controvérsias do campo maior.

Ao finalizar a sua análise, Ianni expóe cinco pontos que procuram " explicitar determinadas singularidades da sociologia, como ciência do social" . Para os que têm trabalhado ao longo desses anos, e aqueles que iniciam a aventura na tentativa de constituir um campo do conhecimento na saúde e que se vêem constrangidos pelas crises, as recomendaçōes de Ianni constituem elementos que podem orientar esta caminhada. Primeiramemte, é apontada a característica fundamental da sociologia - a de pensar-se criticamente, durante todo o tempo; em segundo lugar, a de " reconhecer que o objeto da sociologia é a realidade social em movimento, formação e transformação", revelando principalmente que "o objeto e o sujeito do conhecimento distinguem-se e confundem-se" ; em terceiro lugar, ao considerar que a sociologia é uma forma de auto-consciéncia científica da realidade; em quarto lugar, enfrentar o desafio permanente da relação entre ciencia e arte, teoria e técnica, conhecimento e poder ou teoria e prática; e, finalmente, que na sociologia " o sujeito do conhecimento é individual e colétivo", no sentido que ele se expressa através de "um eu e um nós, um sujeito simultaneamente individual e coletivo do conhecimento".

Reiterar que as ciências sociais colocam-se como fundamentais tanto para as análises conjunturais e estruturais no campo da saúde, e que a construção epistemológica num campo de conhecimento essencialmente interdisciplinar é da maior importancia, chega a ser uma obviedade, mas que necessita ser apontada para que se torne cada vez mais real e extrapole o campo da retórica e do desejo.

\section{REFERENCIAS BIBLIOGRÁPICAS}

1 FOX, R. Reflecions and opportunities in the sociolocy of medicine. J. of Hilbb. soc. Bebav., 26.6-14, 1985.

2 MIILS, C. W. A tmagtmagelo soctolgetca trad. de Waltunair Dutra. Rio de Janeiro, Zahar Bd., 1965.

3 FARIS, R. L. \& DUNHAM, H. W. Mencal disorders in urban aneas. Chicago, University of Chicago Prese, 1939.

4 MERTON, R. K. READER, G. C.; TENDALL, P. L. The studemt-pbystctan Cambridge, Harvard University 
Press, 1957.

5 SROLE, L. et al. Mental bealtb in tbe metropolis. New York, McGraw-Hill, 1962.

6 SIGERIST, H. E. Henry E. Sigerist on tbe soctology of medictine. New York, M. D. Publications, 1960.

7 STERN, B. J. Society and medical progress. Princeton, Princeton Press, 1941.

8 PARSONS, T. The social system, New York, Free Press, 1931.

9 GARCí, J. C. A articulaçăo da medicina e da educaçáo na estrutura social. In: Nunes, E. D., org. Juan Cossar Garcia: pensamento social em saíde na Ambrica Latina Sáo Paulo, Cortez, 1989. p.189-232.

10 ANDRADE, J. Marco conceptual de la educación medica en America Latina (1' Parte). Educ. mod. Salud, 12(1). 1977.

11 NUNES, E. D. Ciencias sociais em saúde no Brasil: notas para a sua historia. Educ. mód. Salud, 21(2):106-15, 1987.

12 NUNES, E. D. Análise de alguns modelos utilizados no ensino das ciencias sociais nas escolas médicas: bases teoricas. Rev. Saude Públ., S. Paulo, 12.506-15, 1978.

13 BREILH, J. La medicina comunitaria: una nueva policta medica? Rev. mexic. Clenc. poltt. soc., 84.5781, 1976.

14 DONNANGelo, M. C. F. \& PEREIRA, L. Saude e sociodade. Säo Paulo, Duas Cidades, 1976.

15 OSHIRO, J. H. Educaçăo para a saúde nas instituiçbes de saúde pública. Sáo Paulo, 1988. [Dissertaçáo de Mestrado - Pontificia Universidade Católica de Sấ Paulo].

16 SEPULLEDA, O. La investigación en ciencias de la conducta y medicina en Latinoamerica. In: Badgety, R. F., ed. Ciencias de la conducta y emsemdneza mudica en Ambrica Latina. New York, Fundación Milbank Memorial, 44(2):55-74, 1966.

17 MENENDEZ, E. L. Antropologta midica: ortentaciones, destgualdades y transactomes. MExico, CLESAS, 1990. p. 5-24: Antropologfa médica en America Latina: una história que recomienza.

18 GARCfh, J. C. Paradigmas para la ensenanza de las ciencias sociales en las escuelas de medicina. Bduc, mbd. Salud, S(2), 1971.

19 NUNES, E. D. A Medicina como profiselo: contribuiça so eatudo da escolha ocupacional entre os catudantes de medicina. Campinas, 1976. [Tese de Doutorado, Faculdade de Ciencias Medicas da UNICAMP].

20 GARCtA, J. C. La educactón mudica en la Amfrica Latina Washington, Organizaça Panamericana de la Salud, 1972.

21 GAETE, J. \& TAPU, I. Ciencias sociales: una discusion acerca de su enfoque en medicina. Cuad. mid. Soc, Santiago, $Y(2): 32-7,1970$.

22 OPSPMS. Aspectos teoricos de las Clencias Sociales aplicadas a la medicina. Bduc mid. Salud, 8(4):354-59, 1974.

23 GOFPMAN, E. Bettgma: la Ldentidad docertorada, trad. Leonor Guinsberg. Argentina, Ammorrotu, 1970.

24 BLOOM, S. W. The doctor and bis pationt. New York, Ruscel Sage Foundation, 1963.

25 MECHANIC, D. Medical soctology. New York, Free Press, 1978.

26 POLACK, J. C. La mudicine du captial. Paris, Maspero, 1971.

27 BERLINGUER, G. Medicina y soctedad Barcelona, Fontanella, 1972.

28 ROSEN, G. Evoluçáo da medicina social. In: Nunes, E. D., org. Medictna soctal: aspectos bistortcos a todricos. Sáo Paulo, Global, 1983. p.2s-82.

29 FREIDSON, E. Profesetional dominancs: the soctal structure of medical practica. Chicago, Nldine Publishing 
Co., 1970.

30 CANGUIIHEM, G. Lo nommal y lo patolbgico. Buenos Aires, Ed. Siglo XXI, 1971.

31 BACHELARD, G. O novo esptrito cientffico; trad. Juvenal Hahne Júnior. Rio de Janeiro, Tempo Brasileiro, 1968.

32 FOUCAULT, M. El nascimiento de la clinica Mexico, Ed. Siglo XXI, 1972.

33 BORDIEU, P. La reproduction. Paris, Editions Minuit, 1970.

34 FICHANT, M. \& PECHEU, M. Sobre la bistorita de las ctenctas. Buenos Aires, Ed. Siglo XXI, 1971.

35 KOSIK, K. Dialbtica do concreto; trad. C. Neves \& A. Toribio. Rio de Janeiro, Paz e Terra, 1976

36 LUKÁCS, G. Historia y consctencta de clase; trad. M. Sacristán. Barcelona, Grijalbo, 1975.

37 ALTHUSSER, L. \& BALIBAR, E. Para loer el Capital. Merico, Siglo XXI, 1970.

38 POULANTZas, N. Poder politico e clasess soctads; trad. Francisco Silva. Salo Paulo, Martins Fontes, 1977.

39 GRAMSCI, A. Os intelectuais e a organizagdo da cultura. Rio de Janeiro, Civilizaça Brasileira, 1968.

40 GARCIA, J. C. As cilncias sociats am modictina In: Nunes, E.D., org. ref. 11, p. $51-67$.

41 MERCER, H. As contribuiçoes da sociologia a pesquisa em saúde. In: Nunes, E. D. As ctlnctas soctads em saitide na Amirica Latina: tendinctas e perspectivas Brastlia, Organizaça Panamericana de Saúde, 1975. p.221-32.

42 TEXXIRA, S. M. F. As ciencias sociais em saúde no Brasil. In: Nunes, E.D., org. ref. 41, p.87-109.

43 DONNANGELO, M. C. F. A pesquisa na área da saúde coletiva no Brasil: a decada de 70. In: ABRASCO. Ensino da saide publica, medictina preventiva e social no Brastl. Rio de Janeiro, 1983. p.19-35.

44 NUNES, E. D. Tendencias e perspectuvas das pesquisas em ciencias sociais em saúde na America Latina: uma visto geral. In: Nunes, E.D., org. ref. 41, p.31-79.

45 TELXEIRA, S. M. F. Op. cit. ref.42. ABRAsCO. Relatorio de Reunito em Camambu, 27-30/11/1988.

46 NUNBS, E. D. As ciencias sociais nos planos de estudo de graduaçáo e pbe-graduaçao. In: Nunes, E.D., org. ref. 41, p. $427-55$.

47 COHN. A. e NUNBS, E. D. A posgraduagdo em sadido colotiva: mestrado e doutorado. Rio de Janeiro. ABRASCO., Rio de Janeiro, 1988, p.15-26. Botudos de Saúde Coletiva, n 5.

48 NUNES, E. D. Blbliografia latinomamericana do ctinctas soctads aplicadas d saride. Brasilia, Organizaçio Panamericana de Saúde, 1987.

49 BADGLEY, R. P., et. al. Btbllografia latimodmericana de clenclas sociales aplicadas a la salud Washington, Organizacion Panamericana de la Salud, 1980.

50 CANBSQUI, A. Antropologia e alimentaglo. Rev. Sadado Pabl, S. Paulo, 223):207-16, 1988.

51 GOLDVATER, C. La medicine tradivionelle en America Latina. In: Bannerman R. et al, org. Mudictme tradttonalle of coweverture des sotns de sance. Geneve, OMS, 1983. p.37-50.

52 QUEIROZ, M. de S. a CANBSQUL, A. Contribuiçbes da antropologia a medicina: uma revisto de estudos no Brasil. Rov. Saride Pabl, Sto Paulo, 20(2):141-51, 1906.

53 DONNANGELO, M. C. F. Medictna - soctedads: o medleo e seu marcado do traballo. Sá Paulo, Livraria Pioneira Ed., 1975.

54 AROUCA, A. S. da S. O dilema preventivise: contribuiçato para a compreensilo e crítica da medicina preventiva. Campinas, 1975. [Tese de doutorado - Paculdade de Ciencias Medicas da UNICAMP]. 
55 NOGUEIRA, R. P. Medicina interna e cirurgia: a formaçáo social da prática médica. Rio de Janeiro, 1977. [Dissertaçăo de Mestrado - Instituto de Medicina Social da Universidade do Batado do Rio de Janeiro].

56 GONChALVES, R. B. M. Medicina e historia: raízes sociais do trabalho médico. Salo Paulo, 1979. [Dissertaça de Mestrado - Faculdade de Medicina da USP].

57 PEREIRA, J. C. de M. A explicaçăo sociologica na medicina social. Ribeiräo Preto, 1983. [Tese de Livre-Docencia - Faculdade de Medicina de Ribeirao Preto da USP].

58 BRAGA, J. C. A questáo da saúde no Brasil. Campinas, 1978 [Dissertaçáo de Mestrado - Instituto de Filosofia e Ciencias Humanas da UNICAMP].

59 LUZ, M. T. As institutgoies midicas no Brastl: instituigdo e estratigla de begmonia Rio de Janeiro, Graal, 1978.

60 COHN, A. Preetalincia soctal e processeo polttico no Brastl. Salo Paulo, Bd. Moderna, 1981.

61 GIFFONL, M. R. Assistencia medica e relaçós de trabalho na empresa: o modelo de convenio com a previdenciasocial. Sáo Paulo, 1981 [Dissertaça de Mestrado - Faculdade de Filosofia e Ciencias Humanas da USP].

62 OLIVEIRA, J. A. \& TEIXEIRA, S. F. A (im)preutdincta soctal: 60 anos da proutdincta soctal no Brastl. Rio de Janeiro, Vozes/ABRASCO, 1986.

63 MACHADO, R., et. al. Danagio da norma: a medictna soctal e constitutgeio da psiguiatria no Brastl. Rio de Janeiro, Graal, 1978.

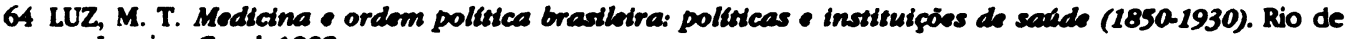
Janeiro, Gral, 1982.

65 MERHY, E. E. O captialismo e a sadis pablica Campinas, Papirus, 1985.

66 LABRA, M. E. O movimento sanitarista dos anos 20: da conexbo sanicaria internacional a especializaça em saúde pública no Brasil. Rio de Janeiro, 1985 [Dlsertaço de Mestrado - Pundaçlo Getúlio Vargas da BAAP].

67 BSCORA, S. A reviravolon na saúde: origem e articulaçio do movimento saniturio. Rio de Janeiro, 1987 [Disereraçio de Mestrado - Bscola Nacional de Saude Pública da Fiocrua].

68 CAMPOS, G. W. de S. Os medlows a politica de sade. Sto Paulo, HUCITEC, 1988.

69 GIOVANNL, G. A questo dos remedios no Brail: produçio e consumo. Polis, SAso Paulo, 19a0. BARROS, M.BA. saude e classe social: um estudo sobre morbidade e consumo de medicamentos. Ribeirso Preto, 1983 [Tese de Doutorado - Paculdade de Medicina de Ribeirlo Preto da USP].

70 CORDEIRO, H. A Indherta de sabde no Brasth Rio de Janeiro, GraalCBaEs, 1980.

71 TEXXIII, S. F., org. Reforma santedria: un busca de uma toorta Sao Paulo, Cortea/ABRASCO, 1909.

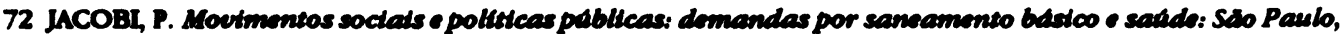
197484 Salo Paulo, Corter, 1909.

73 LUUEI, A. C. \& NORIEGA, M. Processo de produgio e sadds: trabalbo e desegaste operdulo; trad. A. Cohn et. al. Seso Paulo, Hucitec, 1909.

74 BRaIr., J. Epidemiologia: cocnomila, medlatna y politica Santo Domingo, SESPAS, 1981.

75 FRANCO, S. As doenģas tropicais; da anallise de "fecores" a antlise de "procescos". In: Nunes, E. D., org., ref. 41, p. 293-30s.

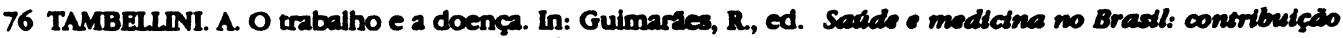
para um dobace. Rio de Janeiro, Graal, 1978.

77 CALDAS Jr., L. Bpidemiologia e controle da doença de Chagas: relaçio com a estrutura agrária na regitso de Sorocaba. Sto Paulo, 1990 [Diserraglo de Mestrado - Paculdade de Medicina da USP]. 
77 LITVOC, J. Doença de Chagas e processo migratório no Bsado de SAso Paulo. Säo Paulo, 1980. [Disseraça de Mestrado, Faculdade de Medicina da USP]; GOLDBAUM, M. Doença de Chagas e trabalho em Área urbana. Sto Paulo, 1979 (Dissertaço de Mestrado, FM/USP); SILVA, L. J. A evoluço da doença de Chagras no Bstado de Sto Paulo. Ribeirao Preto, 1981 [Tese de Doutorado, Faculdade de Medicina de Ribeiráo Preto da USP].

78 BARATA, R. de C. B. Mentingte: uma doenga sob comsurap sajo Paulo, Cortez, 1978.

79 RUFFINO NETTO, A. \& PEREIRA, J. C. Mortalidade por tuberculose e condiçbes de vida: o caso do Rio de Janeiro. Saride em Dob., (12):24-34, 1981.

80 NOGUEIRA, R. P. Pessoal de saúde: a discusesto tebrica e a produço cientifica sobre o tema. In: Nunes, E. D. ref. 41, p. 391407.

81 PAIM, J. S. Medicina preventiva e social no Brasil: modelos, crises e perspectivas. Sarde cm Deb. (11):57-9; 1981.

82 SCHRJBER, L. Educagdo midica e capitalismo. Sto Paulo, HUCITEC/ABRAsCO, 1989.

83 LIMA, J. C. de S. Bducaçăo e prática médica: os movimentos de educaçlo medica na América Latina. Rio de Janeiro, 1983. [Dissertaça de Mestrado - Instituto de Medicina Social da Universidade do Bsmado do Rio de Janeiro].

84 RIBEIRO, C. M. P. De estudante de medicina a medico no interior: formacto e vida profisaional isolada em pequenas cidades de vinte e dois medicos egressos da Universidade Federal de Minas Gerais, de 1978 a 1985. Campinas, 1991. [Tese de Doutorado - Faculdade de Educaço da UNICAMP].

85 MDAYO, M. C. D. S. O desafio do conhecimento: metodologia de pesquisa social (qualimuiva) em saúde. Rio de Janeiro, 1989. [Tese de Doutorado, Escola Nacional de Saúde Pública da FIOCRUZ].

86 LUZ, M. T. Natural, racional, soctal: rasilo medica e racionalidade clenstfica moderna Rio de Janeiro, Campus, 1988.

87 ABRASCO. Catdlogo de pos-graduagio em saddo colottua: Brasth, 1991. Rio de Janeiro, 1991.

88 UGALDE, A. Ciencias sociales y la administracion: ensentinza e investigación de la salud: un caso de subordinacion, subversión o subdesarrollo térico? Birmigham. University of Alabama, 1988, p.37-56. Sparikman Center Series in International Health, $n^{\circ} 1$.

89 SPINEILI, S. P. Caracterizaço dos profiseionais que atuam na trea da saúde, com metodologia das ciencias sociais. In: Adorno, R.F. Org. Prequitea soctal em satedo. Sso Paulo, Cortien, 1992 [no prelo].

90 LAUREI, A. C. E estudio social del proceso saludenfermedad en America Latina. Cuad. med. Soc., Santiago. 7:3-18, 1906.

91 IANNL, O. A crise dos paradigmas em sociologia. Campinas, Instituto de Filosolia e Ciencias Humanas da UNKCAM, 1909. [mimeo]. 